\title{
The FinTech Evolution and Its Effect on Traditional Banking in Africa-A Case of Zambia
}

\author{
Edward Iluba1, Jackson Phiri² \\ ${ }^{1}$ Graduate School of Business, The University of Zambia, Lusaka, Zambia \\ ${ }^{2}$ Department of Computer Science, School of Natural Sciences, The University of Zambia, Lusaka, Zambia \\ Email: edwardiluba@yahoo.com, jackson.phiri@cs.unza.zm
}

How to cite this paper: Iluba, E., \& Phiri, J. (2021). The FinTech Evolution and Its Effect on Traditional Banking in Africa-A Case of Zambia. Open Journal of Business and Management, 9, 838-850.

https://doi.org/10.4236/ojbm.2021.92043

Received: December 31, 2020

Accepted: March 28, 2021

Published: March 31, 2021

Copyright (๑) 2021 by author(s) and Scientific Research Publishing Inc. This work is licensed under the Creative Commons Attribution International License (CC BY 4.0).

http://creativecommons.org/licenses/by/4.0/

(c) (i) Open Access

\begin{abstract}
The popularization of FinTechs has sparked new competition for banks as FinTechs are said to be more convenient, efficient and faster unlike bureaucratic requirements of financial institutions such as banks. The aim of this study was to assess the factors leading to adoption of FinTech financial services and how this affects traditional banking in Zambia. The objectives of the study were to evaluate factors influencing the adoption of FinTech financial services and to develop strategies that can help banks to remain relevant and competitive. The study adopted a quantitative research approach to collect data through self-administered questionnaires. The sample size was arrived at using the Cochran formula. The respondents were selected based on a convenient sampling technique which is a non-probability sampling method. The study adopted the diffusion of innovation theory whose variables were used to come up with hypotheses. The data collected through the questionnaires was analyzed using Pearson Correlation and the SPSS software. Results indicated a strong positive correlation of 0.450 between relative advantage and adoption. Further, the study shows that there is a strong positive correlation of 0.621 between Compatibility and Adoption. The study proposes a revised model that shows factors affecting adoption of an innovation that might help banks.
\end{abstract}

\section{Keywords}

Financial Technology, Adoption, Diffusion of Innovation, Mobile Money

\section{Introduction}

Banking and the financial system as we have known them have been integral to 
the successful establishment of world economies globally. From the early years of modern civilization to the different industrial revolutions, banking has been a major contributor to gross domestic product fueling economic growth for most countries across the world. Just like any other form of change being experienced in different sectors, banking too has evolved over the years and continues to exhibit unprecedented change world over. From the introduction of Automated Teller Machines (ATM) in 1967 in Europe by Barclays Bank to the use of block chain technology in 2009 which uses cryptocurrency to facilitate payments and transfers, technology continues to shape the future of banking. The provision of banking services has for a long time been led by commercial banks that are licensed by Central Banks. In Zambia today, there are about 22 registered commercial banks through which the Bank of Zambia issues currency to facilitate trade (www.boz.zm). The role of commercial banks among others, is to facilitate the establishment of a financial system through which demand and supply of currency are done. Banks would for a long time be the channel through which payments would be facilitated and remained the common mode for savings, sending and receiving money. It was therefore common that one needed to hold an account with a bank through which they would perform banking transactions including using the bank account as a salary point. The growing trend towards the need for fast and efficient payment solutions for most people globally has led to the popularization of digital mobile payment platforms leveraging technology (Flejterski \& Labun, 2016). Away from the long list of requirements for opening a bank account such as valid identification, letter of reference, proof of residence, passport sized photo is an emerging demand for mobile money services that are providing financial solutions for people worldwide.

Deployment of technology has emerged as an alternative form of providing banking services to clients without having to rely on costly physical branch structures (Gu, Lee, \& Suh, 2009). Financial technology (FinTech) refers to the ecosystem of companies that apply technology to facilitate mobile financial transactions thereby disrupting traditional banking (Dorfleitner, Hornuf, Schmitt, \& Weber, 2017). FinTech companies are not registered commercial banks but are payment service providers that use technology to facilitate payments on mobile handsets or electronic devices. The terms mobile money, mobile wallet and mobile transfers are therefore used interchangeably. Advancements in technology have opened the financial sector to a new form of banking leveraging technology. This is commonly referred to as Financial Technology better known as FinTech. FinTech companies facilitate payments and funds transfers via electronic media without clients necessarily having to own a bank account. Examples of global FinTech giants include companies such as Apple (Apple Pay), PayPal, Amazon (Amazon Pay), and Google (Google Pay). A 2018 report by Mckinsey suggests that over USD 1.9 trillion was transacted through digital mobile platforms in 2017. The rise of FinTech companies has also been notable in Zambia with such companies including Zoona, Zazu, Zamtel, Airtel, Kazang, MTN and 
Speedy Pay among others actively facilitating payments.

The rapid growth of players in this new sector means increased participation in financial payments space which is predominantly home for commercial banks while the FinTech companies remain exempted from the regulations that govern commercial banks. "Banking is essential, but Banks are not" is a statement that was made by Bill Gates in 1994 which has served as a mantra for the first wave of financial technology offering banking services ${ }^{1}$. The popularization of products and services covering lending and payments by FinTech companies has sparked new competition for banks as FinTechs are said to be more convenient and faster unlike bureaucratic requirements of financial institutions such as banks, building societies, credit unions and asset management firms. Both incumbents (banks) and new entrants (FinTechs) have unique capabilities that others may not have or may not very easily attain (Conner, 1991).

The competitive advantage of FinTech companies rests in their ability to use technology to distribute and aggregate financial services (www.equities.com). Where does this growing phenomenon leave the traditional banks and does the increasing popularity of FinTech companies mean the end of traditional banking in Zambia? This study will identify the factors that are contributing to the growth of FinTech in Zambia and the effect that this trend is having on traditional banking in Zambia.

\section{Theoretical Framework}

Research conducted around the use of technology in banking has employed the application of several research models and theories to explain factors that lead to adoption of technology. Among the notable models are Technology Acceptance Model (TAM), Unified Theory of Acceptance and Use of Technology (UTAUT), Theory of Reasoned Actions (TRA) and Diffusion of Innovation Theory to mention but a few. This research will focus on the Diffusion of Innovation Theory. Due to the many competing theories and models that exist to explain technology acceptance, the most promising models with the ability to predict and explain individual behavior towards the acceptance and usage of technology are adopted (Dulle \& Majanja, 2011).

Diffusion of Innovation Theory (Roger, 1995) investigates the characteristics of technology adopters who accept innovative technology. This theory seeks to explain why, how, and at what rate new ideas or technology spread. Roger (1995) defines diffusion as the process by which an innovation gets popularized through a social system overtime. Daka and Phiri (2019) define electronic channels as an alternate way to traditional banking. In the context of technology acceptance, this theory underpins the cognitive steps that individuals go through to gain awareness of the innovation and eventually begin to use the innovation. The diffusion of innovation theory emphasizes the four main elements at the center of any innovation, these being the innovation itself, communication

${ }^{1}$ www.hernaes.com. 
channel, social system and time (Wani \& Ali, 2015). Roger (1995) further points out that the decision-making process is specific to individuals but will most likely be influenced by others within the social system. A practical innovation example is "WhatsApp", a popular social media app which allows users across the globe to stay in touch through messaging, video calling and sharing personal photos.

DIFFUSION OF INNOVATION MODEL

In Figure 1 below, Rodger (1995) proposes the diffusion of innovation theory to explain the factors that drive the technology adoption.

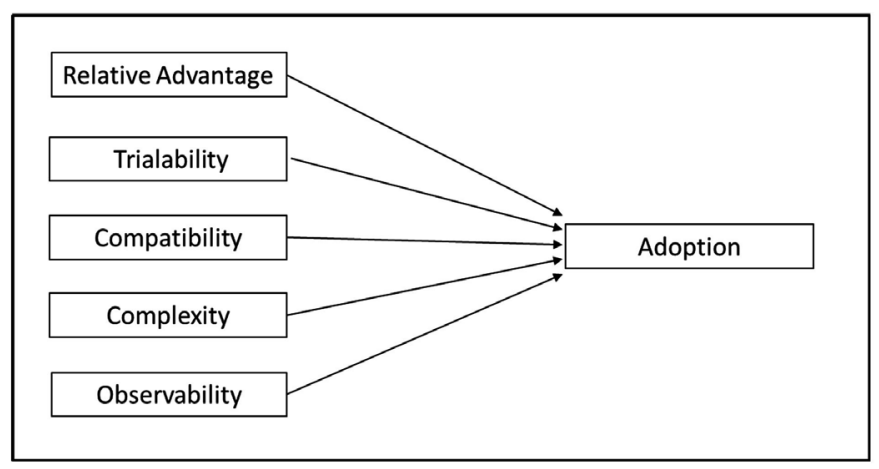

Figure 1. Diffusion of innovation theory (Rodger, 1995).

Relative advantage:

This characteristic discusses the perceived value that the innovation will bring to users and is mostly compared to what is currently available. Believing that the said innovation has the ability to improve one's life is a starting point to arousing interest for the innovation to be adopted (Wani \& Ali, 2015). The adoption of an innovation starts with the question "what's in it for me?". This characteristic is perhaps the single most important element of the innovation adoption process as a user seeks to understand what benefit this innovation brings. How it changes their lives or makes them any better off than they previously where is going to be a strong motivation. Roger (1995) emphasizes that the innovation should demonstrate an improvement to one's way of doing things.

Trialability:

Trialability involves the willingness of users to try out the innovation (Wani \& Ali, 2015). The growth of FinTech innovations such as mobile money as an acceptable channel for payments would require one to register their mobile number for mobile money then proceed to try sending and receiving funds. Similarly, the same also applies for people operating bank accounts. The extent to which someone will be willing to use banking innovation requires that they first try to use the actual innovation.

Observability:

Understanding the results of the performance of innovations after trying them can be a compelling reason for one to try out the innovation or not to (Yousafzai, 2012). Whether observing from personal experience or through the expe- 
riences of others, this characteristic is important towards creating one's affirmation if the innovation is useful to their well-being (Wani \& Ali, 2015).

Complexity:

The ease of use of any innovation makes it worth the while for people to adopt the innovation (Rodger, 1995). If the innovation is difficult to use, it is very likely that users will not be moved towards using the innovation. Sakala and Phiri (2019) reveal the findings of perceived ease of use of an innovation are critical to its adoption.

Compatibility:

This refers to how an innovation fits into one's lifestyle or current conditions. Users would expect that the innovation should not cause them to have such a huge or significant change or shift from what they consider to be their norms.

\section{Literature Review}

Arner et al. (2015) define FinTech as technology-enabled entities delivering financial services ordinarily believed to have been provided by banks. Rodgers (1995) broadly defines innovation as new and creative ways or solutions to known problems. Innovation is mostly inherent with the FinTechs. The outcome of the 2008/9 global financial crisis is that regulators and customers world over had very little trust in banks (Arner et al., 2015). Regulators would now go a step further to critically scrutinize the behavior of banks to avoid reoccurrence of the global melt down and possibility of bank failures (Macey \& O'Hara, 2016). This meant that people now became more trusting of FinTechs than banks thus becoming more open to consuming FinTech products.

Banks have adopted a different way of innovating to respond to the changing competitive environment and the FinTech boom (Flejterski \& Labun, 2016). Digitalization of operations to mainly create a much leaner and faster operation has been at the center of digitalization in the banking industry. Schreiber and Vrielink (2019) define FinTech as financial innovation brought about by technology.

Among the notable issues that impede innovation in banks is the obsolete information technology infrastructure and the high switching costs (Flejterski \& Labun, 2016). Bergers et al. (2014), attribute the explosion of entrepreneurship and rising culture of startups as the pathway for FinTech companies. This is to the effect that most banks are now setting up venture capital funds specialized in FinTech support and in some cases acquisition (Temelkov, 2018). This posture is directed towards banks repositioning themselves to respond to the threat of FinTech companies. Banks have therefore started to find more efficient channels through which they are now servicing their clients. Electronic channels are an alternative to clients being services through branches. Daka and Phiri (2019) define electronic channels as an alternate way to traditional banking. This innovation being pursued by banks also leverages the existence of technology in banking to promote efficiency and convenience. To counter the threat of FinTech, it has become imperative for banks to foster innovation leveraging technology. 
E-channels will seek to provide platform for customers to access banking services without dependency on physical interaction with banks through branches.

Bruijn et al. (2017) provide an in-depth discussion into mobile money. In their report dubbed "An ethnographic study on mobile money attitudes, perceptions and usages in Cameroon, Congo DRC, Senegal and Zambia, they discuss fundamental facets that influence the adoption of mobile money. Mobile money is electronic money distributed or transacted through mobile networks and SIM enabled devices" (Bruijn et al., 2017). This service is mainly distributed by Mobile Network Operators (MNO) such as Airtel, MTN and Zamtel. Mobile Money is part of the service offering that MNOs provide consumers outside voice and data services. MNOs leverage technology to provide mobile money services without being banks themselves. The MNOs therefore fit into the broader definition of FinTechs delivering financial services to clients. Bruijn et al. (2017) further introduce the concept of Digital Financial Services (DFS) which is the broader definition of the full range of financial services offered through digital channels. The advancements in technology will certainly bring with it their own challenges mainly associated with information security and cyber terrorism (Brynjolfsson \& Hitt, 2000).

\section{Methodology}

The research methodology expresses the study's approach to data collection in order to respond to the research questions (Saunders, 2012). A quantitative research design was chosen for this study. Aliaga and Gunderson (2002) define quantitative research as explaining phenomena by collecting numerical data that are analyzed through the use of mathematical methods. Muijs (2004) suggests that quantitative research is especially suited when testing hypotheses where the researcher wants to not only establish if there is a relationship between variables but to also understand the nature of the relationship that exists between such variables. Given the large population of mobile money subscribers in Zambia, Cochran (1963) proposes a mathematical formula to derive at a sample size which is reflective of total population where the given population is too vast to consider.

A convenient non-probability sampling technique was used to randomly select the sample. The sampling frame then comprised individuals in Lusaka that own a mobile wallet. The respondents were selected on the basis of the researcher's judgment. The sample size was arrived at using a statistical formula;

$$
n_{o}=\frac{z^{2} \times p(1-p)}{e^{2}},
$$

where:

- $n_{o}$ is the sample size

- $Z$ is the two tailed area under the normal curve where $\alpha=0.05$ and the $Z$ value is 1.96

- $e$ is the acceptable sampling error 
- $p$ is the population of a proportion with a desired attribute (assumed to be 0.5 which maximizes the sample size to be determined). Given these values and an acceptable sampling error of 6\%, the sample size determined is as

$$
n_{o}=\frac{1.962 \times 0.5(1-0.5)}{(0.06)^{2}}=267
$$

This gave a sample size of 267 to whom questionnaires were administered using convenient sampling targeting bank account holders and mobile money users.

The respondents were selected based on the researcher's judgment about which respondents' ability to constructively provide relevant respondents to add value to the topic under study.

Structured questionnaires were dispensed to collect primary data from the respondents. The questionnaire was designed based on the conceptual model in Figure 1 based on the Diffusion of Innovation Model. The questionnaire was split into distinctive sections with the first section mainly covering demographics of respondents while the latter sections focusing on adoption of technology innovation used the variables of the Diffusion of Innovation model to structure questions. To test the reliability and validity of the questionnaire, the completed questionnaire was initially piloted twice with 15 respondents to assess the consistency of the responses.

Data was analyzed using basic descriptive statistics and inference statistics based on Pearson Correlation. The Statistical Package for Social Sciences (SPSS) software was used to analyze the date. Data was presented in form charts and tables.

\section{Results and Discussion}

This section presents the outcome of the study conducted covering the demographic characteristics of the sample population under study.

Demographic Characteristics

The sample size represented $74 \%$ male with the remaining $26 \%$ being female (Figure 2).

$57 \%$ of the respondents were between the age group of $21-30,20 \%$ were between the age of $31-40$ while respondents between the age of $41-50$ and $51-60$ were both at $3 \%$ respectively. $79 \%$ owned a bank account while $21 \%$ did not own bank accounts. However, $100 \%$ of the respondents owned a mobile wallet (Figure 3).

Table 1 shows that people would either open a bank account or a mobile wallet or both. The results showed that 212 representing $79.4 \%$ of the respondents own a bank account and 55 representing $20.6 \%$ of the respondents stated that they don't own a bank account. On the other hand, 267 representing $100 \%$ of the respondents had a mobile wallet. 


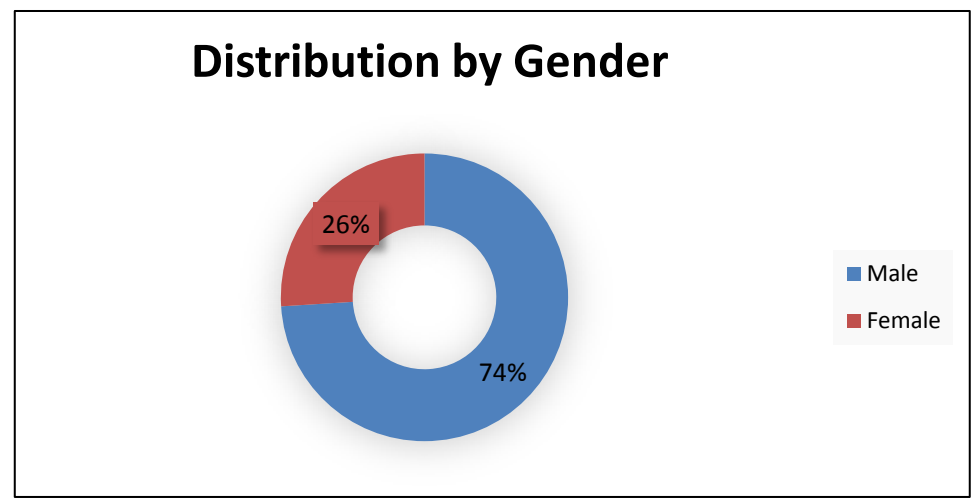

Figure 2. Gender distribution.

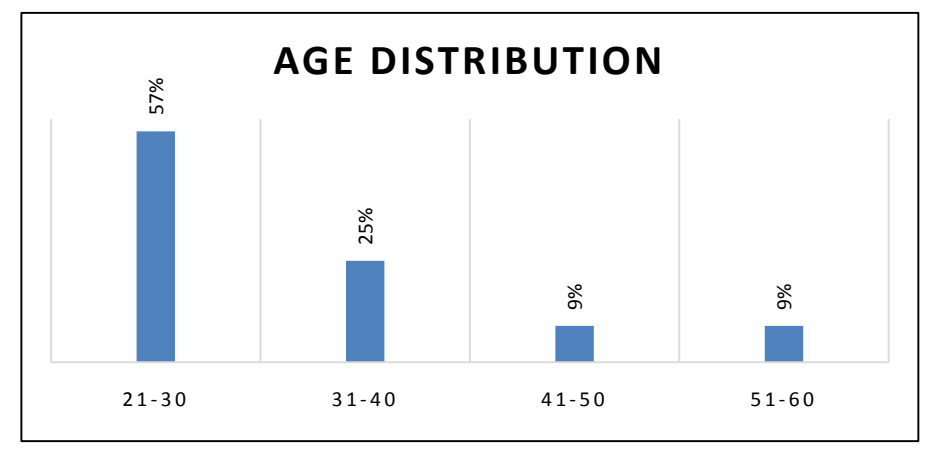

Figure 3. Age distribution.

Table 1. Gender and owning a bank account and mobile wallet.

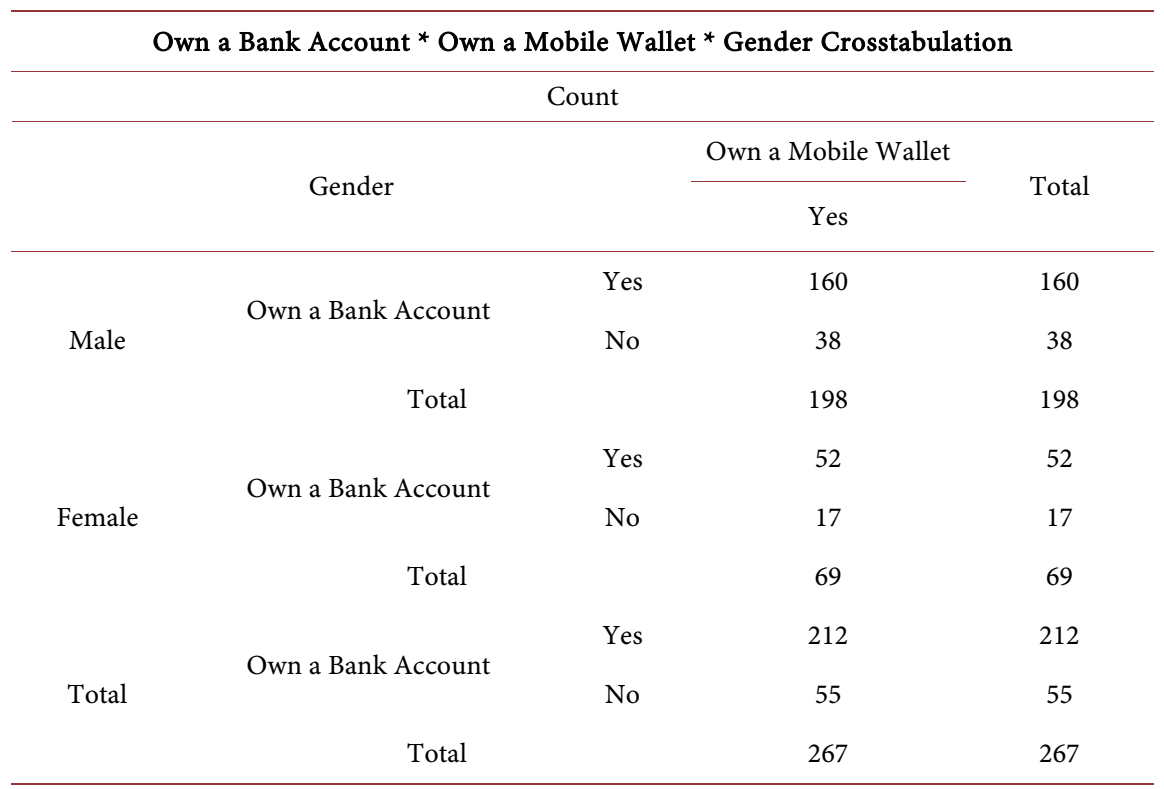

A total of 198 males participated in the study among whom 160 owned both a bank account and mobile wallet and 38 males had only a mobile wallet. On the other hand, a total of 69 females participated in the study among whom 57 owed both a bank account and a mobile wallet and 17 owned only a mobile wallet. 


\section{Correlation Analysis}

After conducting a correlational analysis, the following relationships in relation to the hypothesis were generated: test for significance holds that if the $p$-value $\leq$ 0.05 or 0.04 accept the research hypothesis but if the $p$-value $>0.05$ or 0.01 reject the research hypothesis. 0.05 or 0.01 are the default significant level that is determined by the size of the $p$-value, if the $p$-value is too small 0.01 is used and if the $p$-value is relatively large 0.05 is used.

Relative advantage and Adoption

The study showed that there is a significant relationship between Relative Advantage and Adoption as the $p$-value of 0.000 is less than the significant level of 0.01 . Further, the study shows that there is a strong positive correlation of 0.450 between relative advantage and adoption as shown in Table 2 .

Trialability and Adoption

A further analysis on Trial Ability showed that there is a significant relationship between Trial Ability and adoption as the p-value of 0.000 is less than the significant level of 0.01 . Further, the study showed that there is a positive relationship of 0.225 between Trial Ability and adoption as shown in Table 3.

Observability and Adoption

A test on observability and Adoption indicated a significant relationship with a $p$-value of 0.000 which is less than the significant level of 0.01 . However, the analysis showed that there is a weak negative relationship of -0.219 between Observability and Adoption as shown in Table 4.

Complexity and Adoption

The study established that there is no significant relationship between Complexity and adoption as the $p$-value of 0.880 is greater than the significant level of 0.05 . Further, the study showed that there is a very weak negative correlation of -0.009 between Complexity and Adoption as shown in Table 5 .

Compatibility and Adoption

Finally, the study showed a significant relationship between Compatibility and Adoption as the $p$-value of 0.000 is less than the significant level of 0.01 . The study showed that there is a strong positive correlation of 0.621 between Compatibility and Adoption as shown in Table 6.

Table 2. Correlational analysis between relative advantage and adoption.

\begin{tabular}{ccc}
\hline & & $\begin{array}{c}\text { Preference for } \\
\text { sending/receive money }\end{array}$ \\
& Pearson Correlation & $0.450^{* *}$ \\
Relative Advantage & Sig. (2-tailed) & 0.000 \\
$\mathrm{~N}$ & 267 \\
\hline
\end{tabular}

**. Correlation is significant at the 0.01 level (2-tailed). 
Table 3. Correlational analysis between trial ability and adoption.

\begin{tabular}{ccc}
\hline & Preference for sending/receive money \\
\hline Trial Ability & Pearson Correlation & $0.225^{* *}$ \\
& Sig. (2-tailed) & 0.000 \\
$\mathrm{~N}$ & 267 \\
\hline
\end{tabular}

**. Correlation is significant at the 0.01 level (2-tailed).

Table 4. Correlational analysis between observability and adoption.

\begin{tabular}{ccc}
\hline & & Preference for sending/receive money \\
\hline & Pearson Correlation & $-0.219^{* *}$ \\
Observability & Sig. (2-tailed) & 0.000 \\
$\mathrm{~N}$ & 267 \\
\hline
\end{tabular}

**. Correlation is significant at the 0.01 level (2-tailed).

Table 5. Correlational analysis between complexity and adoption.

\begin{tabular}{ccc}
\hline & & Preference for sending/receive money \\
\hline Complexity & Sig. (2-tailed) & -0.009 \\
$\mathrm{~N}$ & 0.880 \\
& 267 \\
\hline
\end{tabular}

**. Correlation is significant at the 0.01 level (2-tailed).

Table 6. Correlational analysis between compatibility and adoption.

\begin{tabular}{ccc}
\hline & Preference for sending/receive money \\
\hline Compatibility & Sig. (2-tailed) & $0.621^{* *}$ \\
$\mathrm{~N}$ & 0.000 \\
& & 267 \\
\hline
\end{tabular}

$\star *$. Correlation is significant at the 0.01 level (2-tailed).

\section{Conclusion and Recommendations}

The diffusion of innovation theory proposed by Rodger explains the extent to which innovations will be successful and the factors that enhance the adoption of such innovations. The results of the correlation analysis were based on the diffusion of innovation model from which the proposed characteristics that drive innovation adoption were hypothesized. After conducting a correlational analysis, the following relationships in relation to the hypothesis were generated:

The study showed that there is a significant relationship between Relative Advantage and Adoption as the $p$-value of 0.000 is less than the significant level of 0.01 . Further, the study shows that there is a strong positive correlation of 0.450 between relative advantage and adoption.

A further analysis on Trial Ability showed that there is a significant relation- 
ship between Trial Ability and adoption as the $p$-value of 0.000 is less than the significant level of 0.01 . Further, the study showed that there is a positive relationship of 0.225 between Trial Ability and adoption.

Finally, the study showed a significant relationship between Compatibility and Adoption as the $p$-value of 0.000 is less than the significant level of 0.01 . Further, the study shows that there is a strong positive correlation of 0.621 between Compatibility and Adoption.

The analysis also revealed non-existence of a significant relationship between observability and adoption. The analysis further nullified any significant relationship between compatibility and adoption.

While banks remain number one choice for providing financial services to corporate entities, it worth acknowledging that individuals are preferring using mobile money to send and receive money than banks. To counter the dominance of FinTech and to improve adoption of banking services, below recommendations are being proposed:

1) Banks should reduce requirements for opening bank accounts. Mandatory requirements such as proof of address and valid Taxpayer's Identification Number ought to be made non-mandatory as not many people will have access to such documents. For instance, a person living in a rented house without a lease agreement will not be able to produce a utility bill bearing their names to confirm proof of address.

2) Banks should consider opening more branches in order to improve access to banking services.

3) Banks should consider extending their operating hours. It was observed that most banks operated between 8 am to $3 \mathrm{pm}$ whereas mobile money booths operated from 8 am to around $8 \mathrm{pm}$ therefore remaining accessible to customers for longer periods. Customers want to do their banking without being restricted to short banking hours.

4) Banks should revise their fees \& charges to make them more affordable.

\section{Acknowledgements}

My sincere gratitude to my supervisor Dr. J. Phiri for his relentless efforts in my work and to all the participants that took part in this research for their support.

\section{Conflicts of Interest}

The authors declare no conflicts of interest regarding the publication of this paper.

\section{References}

Aliaga, M., \& Gunderson, B. (2002). Interactive Statistics. Thousand Oaks, CA: Sage.

Arner, D. W., Barberis, J., \& Buckley, R. P. (2015). The Evolution of FinTech: A New Post-Crisis Paradigm? Research Paper No. 2015/047, Hong Kong: University of Hong Kong, Faculty of Law. https://dx.doi.org/10.2139/ssrn.2676553 
Berges, A., Guillen, M., Moreno, J., \& Ontiveros, E. (2014). A New Era in Banking. The Landscape after the Battle. Brookline, MA: Bibliomotion.

Bruijn, M., Butter, I., \& Fall, A. (2017). An Ethnographic Study on Mobile Money Attitudes, Perceptions and Usages in Cameroon, Congo DRC, Senegal and Zambia. Report No. 128221, Washington DC: World Bank Group.

Brynjolfsson, E., \& Hitt, L. M. (2000). Beyond Computation: Information Technology, Organizational Transformation and Business Performance. The Journal of Economic Perspectives, 14, 23-48. https://doi.org/10.1257/jep.14.4.23

Cochran, W. G. (1963). Sampling Techniques (2nd ed.). New York, NY: John Wiley and Sons, Inc.

Conner, K. R. (1991). A Historical Comparison of Resource-Based Theory and Five Schools of Thought Within Industrial Organization Economics: Do We Have a New Theory of the Firm? Journal of Management, 17, 121-154. https://doi.org/10.1177/014920639101700109

Daka, G., \& Phiri, J. (2019). Factors Driving the Adoption of E-Banking Services Based on the UTAUT Model. International Journal of Business and Management, 14, 43-52. https://doi.org/10.5539/ijbm.v14n6p43

Dorfleitner, G., Hornuf, L., Schmitt, M., \& Weber, M. (2017). The FinTech Market in Germany. Berlin: Springer.

Dulle, W. F., \& Majanja, M. K. (2011). The Suitability of the Unified Theory of Acceptance and Use of Technology (UTAUT) Model in Open Access Adoption Studies. Information Development, 27, 32-45. https://doi.org/10.1177/0266666910385375

Flejterski, S., \& Labun, J. (2016). The Banking Industry and Digital Innovation: In Search of New Business Models and Channels. European Journal of Service Management, 20, 5-15. https://doi.org/10.18276/ejsm.2016.20-01

Gu, J. C., Lee, S. C., \& Suh, Y. H. (2009). Determinants of Behavioral Intention to Mobile Banking. Expert Systems with Applications, 36, 11605-11616. https://doi.org/10.1016/j.eswa.2009.03.024

Macey, J. R., \& O’Hara, M. (2016). Bank Corporate Governance: A Proposal for the Post-Crisis World. Economic Policy Review, 85-105.

Muijs, D. (2004). Doing Quantitative Research in Education with SPSS. London; Thousand Oaks, CA; New Delhi: Sage Publications.

https://doi.org/10.18276/ejsm.2016.20-01

Rogers, E. M. (1995). Diffusion of Innovations (4th ed.). New York, NY: Free Press. https://doi.org/10.4135/9781849209014

Sakala, L., \& Phiri, J. (2019). Factors Affecting Adoption and Use of Mobile Banking Services in Zambia Based on TAM Model. Open Journal of Business, 7, 1380-1394. https://doi.org/10.4236/ojbm.2019.73095

Saunders, M. L. (2012). Research Methods for Business Students (6th ed.). Harlow: Pearson Education Limited.

Schreiber, T., \& Vrielink, T. (2019). The Emergence of FinTech-How Do Established Banks in the Nordics React to the Threat of Fin Tech Disruption?

Temelkov, Z. (2018). Fintech Firms Opportunity or Threat for Banks? International Journal of Information, Business and Management, 10, 138-144.

Wani, T. A., \& Ali, S. W. (2015). Innovation Diffusion Theory Review \& Scope in the 
Study of Adoption of Smartphones in India. Journal of General Management Research, 3, 101-118.

Yousafzai, S. (2012). A Literature Review of Theoretical Models of Internet Banking Adoption at the Individual Level. Journal of Financial Services Marketing, 17, 215-226. https://doi.org/10.1057/fsm.2012.19 